\title{
BIOINFORMATION

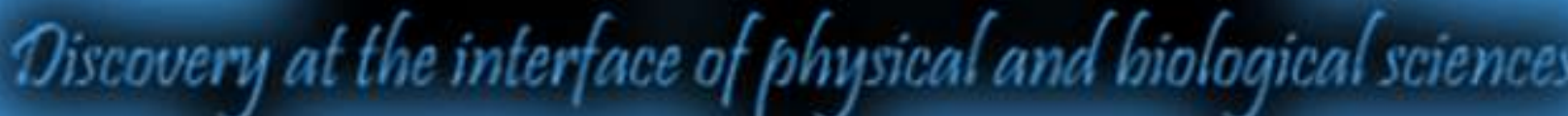

\section{Screening of MicroRNA as potential CardiomiRs in Rattus noveregicus Heart related Dataset}

\author{
Yashika Rustagi \&Vibha Rani*
}

Department of Biotechnology, Jaypee Institute of Information Technology, A-10, Sector-62, Noida, 201307, Uttar Pradesh, India; Vibha Rani - Email: vibha.rani@jiit.ac.in; Tel: + (91)-120-2594210; *Corresponding author

Received August 22, 2013; Revised August 29, 2013; Accepted August 31, 2013; Published November 11, 2013

\begin{abstract}
:
MicroRNAs (miRNAs) are the naturally expressed small, 18 25 nts long non-coding single stranded RNAs, which inhibit the translation by interacting with the 3' untranslated region (UTR) of specific mRNA targets or by repression of posttranscriptional modification of mRNAs. MiRNAs are found to regulate the differentiation, development, function and stress responsive growth of cardiac cells. Their role and association with several disease progressions is of interest in recent years. Our interest is to study their role in cardiac hypertrophy (characterized by increased cell size, protein synthesis and reactivation of gene pathways). Therefore, we analyzed their features using a dataset $(\# \approx 1400 \#)$ of potential intronic and 3 'UTR targeted miRNAs from known cardiac marker genes. We report 10 uncharacterized miRNAs regulating cardiac marker genes during cardiac hypertrophy and other cardiac diseases.
\end{abstract}

\section{Background:}

Defects in cardiovascular system are the leading causes of mortality in present times. Diseases like heart attack, stroke and peripheral vascular disease are the major diseases of the cardiac system [1]. Despite exponential development in the field of cardiovascular research, current therapies, diagnosis and treatments have not sufficed the efficiency of curing these ailments. However appearance of small noncoding microRNAs (miRNAs) over past few years in various physiological and pathological fields including cardiovascular system has opened new opportunities for therapeutic developments [2].

During the time of cellular stress or patho-physiological conditions such as oxidative stress, cardiac cells undergo cardiac hypertrophy, a complex phenomenon that comprises the involvement of numerous intricately connected intracellular signal transduction cascades [3]. These pathways are activated in response to the biomechanical stress conditions that prevail on the heart. The cardiac muscle tries to compensate the tension through an increase in the size of the terminally differentiated cardiomyocytes. This is accompanied with re-expression of genes normally expressed in the fetal heart and an increased protein synthesis [4]. There are certain essential marker genes which play a prominent role to cause cardiac hypertrophy such as alpha-Actinin, Atrial Natriuretic Peptide, Brain Natriuretic Peptide, beta-MHC, Troponin C, MYL2, MYL3, TPM1, TITAN etc. Prolonged cardiac hypertrophy witnesses a transition from physiological to pathological hypertrophy which further progresses towards an increased risk of cardiac failure [5].

The short, endogenously expressed, non-translated microRNAs are involved in various biological processes, which include developmental patterning, differentiation, proliferation, cell death and metabolism. They act as negative regulators of gene expression by inhibiting the translation or promoting the mRNA degradation [6]. These miRNAs are generated by the Dicer which is a multidomain enzyme of the RNase III family [7]. They maintain homeostasis across a wide variety of tissues including the cardiovascular system. Single miRNAs regulate the expression of several of mRNAs that often share related functions and thus govern various biological processes [8]. The diverse functions exhibited by individual miRNAs and the number of miRNAs that are expressed in the cardiovascular system, both lead towards the idea that majority of 
physiological as well as pathological processes in the cardiovascular system may be controlled by miRNAs, at least in parts [9]. There are number of introns encoded miRNAs which are involved in RNAi mediated gene silencing. The majority of human gene transcripts contain introns and changes in these non-protein-coding sequences are frequently observed in clinical diagnosis of myocardial dysregulation and other injuries related cardiac hypertrophy [10]. Therefore, our studies were designed to screen the potential intronic miRNAs which may be characterized further as a key molecule to regulate the cardiac hypertrophy.

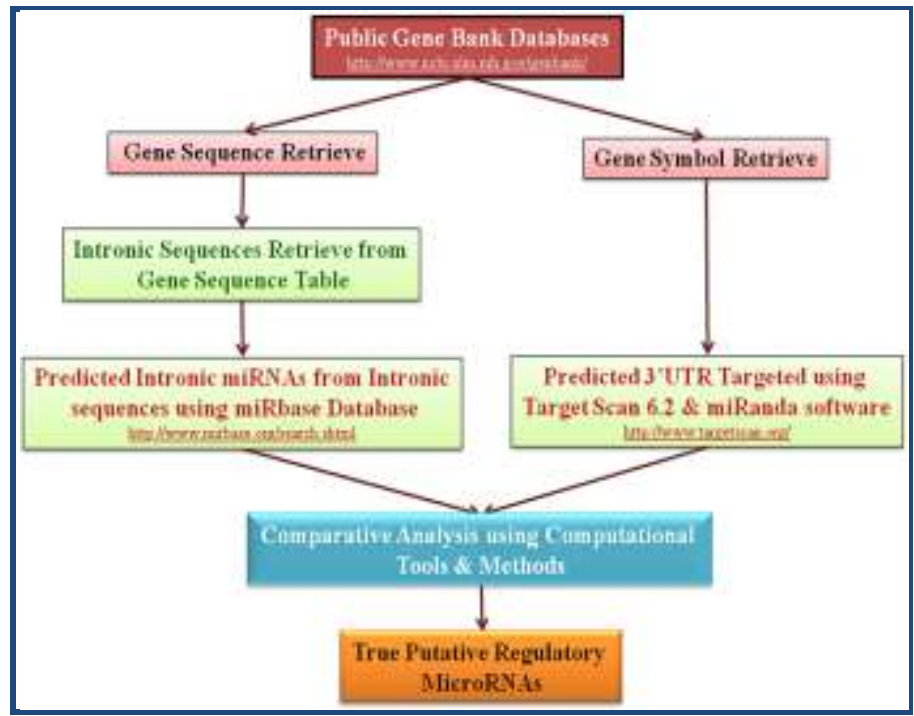

Figure 1: Workflow to screen potential MicroRNAs.

\section{Methodology:}

The work flow to screen the potential intronic and 3' UTR targeted miRNAs is shown in (Figure1).

\section{Sequence dataset}

The complete nucleotide sequences and the intronic sequences associated with the cardiac marker genes from Rattus noveregicus were downloaded from GenBank in FASTA format.

\section{Sequence Analysis}

The miRbase Database (http://www.miRbase.org/) was used for the identification of relevant miRNAs, expressing in heart. The sequences were further confirmed by employing BLASTN, implemented in miRase (http://www.miRbase.org/search.shtml) with default E-value and hit number.

\section{3'UTR Targeted miRNA Prediction}

Target scan (http://www.targetscan.org/) was used to predict 3'UTR targeted microRNAs. Subsequently, Target scan 6.2 (modified version of Target scan) was used for the prediction of conserved and poorly conserved miRNAs from all the 3'UTRs of essential and selected cardiac marker genes (as reference to human and rat).

\section{Comparative analysis of intronic and targeted microRNAs}

A comparative analysis was performed by expanding and sorting the data using several computational tools to find: (1) the true putative regulatory microRNAs, (2) intronic
MicroRNAs, originating from intronic sequences, and (3) 3'UTR targeted microRNAs from 3'UTR of selected cardiac marker genes.

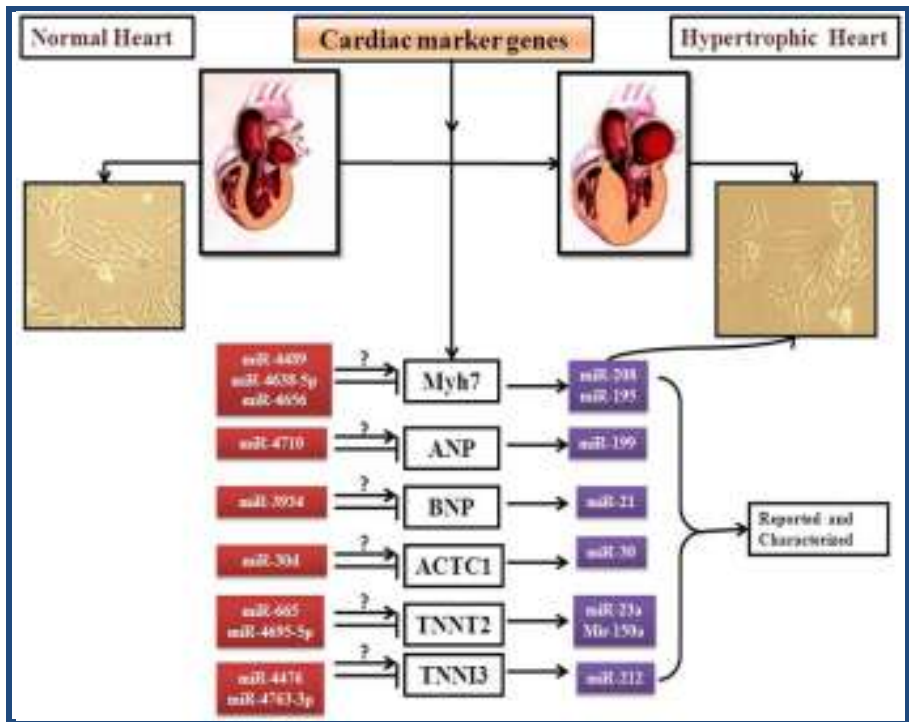

Figure 2: Possible Role of screened microRNAs in cardiac hypertrophy. During cardiac hypertrophy normal heart increases in size due to re-expression of cardiac marker genes (shown in white boxes). We screened 10 potential intronic and 3'UTR targeted microRNAs by analysis, shown in Red boxes, and these microRNAs are originated from intronic sequences of essential cardiac marker genes and these microRNAs are also targeted same cardiac marker genes. Previously reported and characterized microRNAs are shown in purple boxes, also found during our analysis which makes validate our study.

\section{Results \& Discussion:}

MicroRNAs are the potent regulators of gene expression either by inhibiting the posttranscriptional modification or repression of translation. Biogenesis of intronic miRNA and target recognition seems to be mediated through base paring of a 7 $8 \mathrm{Nts}$ short seed sequence in the $5^{\prime}$ region of the miRNAs [11]. Intronic miRNAs are based on two important aspects, (i) they must have the same promoter with their encoded target genes and (ii) they spliced out of the transcript of such encoded genes [12]. During cardiac hypertrophy, stress induced up-regulation of miRNAs featured to the suppression of a set of targeted mRNAs and vice versa due to possible loss of ionic inhibitory control of the miRNA on its target mRNA [13].

For isolating the miRNAs, which may have therapeutics applications for the heart diseases, six essential cardiac marker genes (ANP, BNP, alpha-Actinin, beta-MHC, TNNT2, TNNI3) were studied. Numbers of intronic sequences from all the marker genes were analyzed to screen the miRNAs originating from cardiac marker intronic gene sequences by implementing search and BLASTN in miRBase database. We also analyzed the miRNAs targeting the 3'UTRs of the same cardiac genes by using Target scan and miRanda application. Table 1 (see supplementary material) summarizes the compiled information of the intronic and $3^{\prime}$ UTR targeted microRNAs screened from selected cardiac gene pool.

We found 10 true putative regulatory miRNAs after comparative analysis between the intronic miRNAs and 3'UTR 
targeted miRNAs using computational tools. hsa-Mir-4710, hsaMir-3934, hsa-Mir-665 \& has-Mir-4695-5p, hsa-Mir-4476 \& hsaMir-4763-3p, hsa-Mir-30d, , hsa-Mir-4489 \& has-Mir-4638-5p \& hsa-Mir-4635 in respect to ANP, BNP, TNNT2, TNNI3, aActinin, MYH-7 were identified, as shown in Table 2 (see supplementary material). These 10 true putative regulatory microRNAs are fishing out from the intronic sequences of selected cardiac marker genes and all these 10 potential microRNAs are targeted the same selected cardiac marker genes. Therefore, these 10 true putative regulatory microRNAs can be hypothesized as potential microRNAs regulating the cardiac development and diseases such as hypertrophy where re-expression of fetal genes has been witnessed (Figure 2). These uncharacterized microRNAs can further be studied to understand the mechanism of their effect on cardiac gene program. They may play significant role in regulating the cardiac hypertrophy. After characterizing the role of the miRNAs screened by our insilico study, miRNA mimic and Antimir can be designed for future therapeutics against cardiac hypertrophy.

We also found Mir-208, Mir-22, Mir-29, Mir-30, miR133, miR122, Mir-150, miR23a, Mir-125, Mir-199, miR195, miR196 and Mir-214 during our analysis. The role of some these mirRNAs have already been reported in the heart context. miR23a, Mir-125, Mir-199, miR195 and miR196) has been found to be up-regulated whereas miR133, Mir-29, Mir-30 and Mir-150 down-regulate during hypertrophy [14]. Mir-133 has already been characterized to regulate the myogenesis in adult cardiac and skeletal muscle in mammals [15]. Mir-208 plays a prominent role in the expression of $\beta$-MHC in response to cardiac stress but it appears to show the dominant function in regulating cardiac hypertrophy and remodeling although, the expression level of this Mir-208 remains stable during cardiac stress [16]. MiR-195 was the first characterized miRNAs, which induces the hypertrophy in cultured neonatal rat cardiomyoctes [17]. Over-expression of Mir-199a was found sufficient to increase cell hypertrophy while the antisense oligonucleotide mediated knockdown of Mir-199a was sufficient to decrease cardiomyocyte size [18]. The presence of these already reported miRNAs validate our approach and hypothesize that hsa-Mir4710, hsa-Mir-3934, hsa-Mir-665 \& has-Mir-4695-5p, hsa-Mir4476 \& hsa-Mir-4763-3p, hsa-Mir-30d, and hsa-Mir-4489 \& hasMir-4638-5p \& hsa-Mir-4635 isolated in our study may play an essential role to regulate cardiac marker genes during hypertrophy and other cardiac diseases. invitro and invivo experiments can be conducted in future to understand their expression during cardiac development and diseases.

\section{Conclusion:}

Small changes in actions and modifications in genes affect developmental and regulatory pathways for heart function.
Therefore, it is of interest to characterize their molecular features using miRNAs associated with the heart. We report 10 uncharacterized miRNAs during cardiac hypertrophy in heart through this sequence based computational analysis. The diversity of miRNAs and the complexity of genomic introns are intriguing. Hence, investigation and characterization of disease specific intronic miRNAs and their targets can help in the understanding the corresponding diseases.

\section{Acknowledgement:}

This work was supported by the research grant awarded to Dr.Vibha Rani by the Department of Biotechnology, Government of India (BT/PR3642/AGR/36/709/2011). We acknowledges Jaypee Institute of Information Technology, Deemed to be University, for providing the required support.

\section{References:}

[1] Heineke J \& Molkentin JD, Nat Rev Mol Cell Biol. 2006 7: 589 [PMID: 16936699]

[2] Eva van Rooji \& Olson EN, Nat Rev Drug Discov. 2012 11: 860 [PMID: 23080337]

[3] Kohli S et al. Curr Cardiol Rev. 2011 7: 262 [PMID: 22758628]

[4] Rosca MG et al. J Mol Cell Cardiol. 2013 55: 31 [PMID: 22982369]

[5] Akazawa H \& Komuro I, Circ Res. 2003 92: 1079 [PMID: 12775656]

[6] Oliveira-Carvalho V et al. Mol Biol Rep. 2013 40: 2663 [PMID: 23242657]

[7] Ying SY et al. Methods Mol Biol. 2013 936: 1 [PMID: 23007495]

[8] Lippi G et al. Int J Cardiol. 2013 S0167: 01280 [PMID: 23890863]

[9] Goettsch C et al. Circ Res. 2013 112: 1073 [PMID: 23538277]

[10] Kuo CH et al. Methods Mol Biol. 2013 936: 77 [PMID: 23007500]

[11] Heyn J et al. Methods Mol Biol. 2013 936: 83 [PMID: 23007501]

[12] Lin SL et al. J Biomed Biotechnol. 2006 2006: 26818 [PMID: 17057362]

[13] Van Rooij E et al. Circ Res. 2008 103: 919 [PMID: 18948630]

[14] Ghelani HS et al. I Pharmacol Pharmacother. 2012 3: 217 [PMID: 23129956]

[15] Xiao J et al. J Biol Chem. 2007 282: 12363 [PMID: 17344217]

[16] Diniz GP et al. Mol Cell Endocrinol. 2013 374: 117 [PMID: 23623871]

[17] Van Rooij E et al. Proc Natl Acad Sci U S A. 2006 103: 18255 [PMID: 17108080]

[18] Da Costa Martins PA \& De Windt LJ, Cardiovasc Res. 2012 93: 563 [PMID: 22266752]

Edited by P Kangueane

Citation: Rustagi \& Rani, Bioinformation 9(18): 919-922 (2013) License statement: This is an open-access article, which permits unrestricted use, distribution, and reproduction in any medium, for non-commercial purposes, provided the original author and source are credited 


\section{Supplementary material:}

Table 1: Intronic and 3'UTR Targeted microRNAs

\begin{tabular}{llllll} 
Sr. No. & Gene Name & Gene Accession No. & Intronic sequences & Intronic MiRNAs & $\begin{array}{l}\text { 3'UTR Targeted } \\
\text { MiRNAs }\end{array}$ \\
\hline 1. & Atrial Natriuretic Peptide (ANP) & NM_012612 & 2 & 81 & 47 \\
2. & Brain Natriuretic Peptide(BNP) & M25297 & 2 & 14 & 38 \\
3. & Cardiac Troponin T2 (TNNT2) & EU295527 & 14 & 367 & 68 \\
4. & Cardiac Troponin C3 (TNNI3) & NM_017144 & 7 & 139 & 22 \\
5. & a-Actinin1 (ACTC1) & NM_019183 & 6 & 113 & 5 \\
6. & B-MHC 7 (MyH7) & NM_017240 & 38 & 435 & 33 \\
\hline
\end{tabular}

Table 2: Comparative analysis of Intronic \& 3'UTR Targeted microRNAs

\begin{tabular}{|c|c|c|c|c|c|}
\hline $\begin{array}{l}\text { Sr. } \\
\text { No. }\end{array}$ & Gene Name & $\begin{array}{l}\text { Gene } \\
\text { Accession } \\
\text { No. }\end{array}$ & Gene Function & $\begin{array}{l}\text { True } \\
\text { Putative } \\
\text { Regulators }\end{array}$ & $\begin{array}{l}\text { Gene Function } \\
\text { Studied }\end{array}$ \\
\hline 1. & $\begin{array}{l}\text { Atrial } \\
\text { Natriuretic } \\
\text { Peptide (ANP) }\end{array}$ & NM_012612 & $\begin{array}{l}\text { Sensitive cardiomyocyte marker of ventricular } \\
\text { hypertrophy. }\end{array}$ & hsa-Mir-4710 & $\begin{array}{l}\text { Hiroyama M et } \\
\text { al, 2007, [PMID: } \\
\text { 22758628]. }\end{array}$ \\
\hline 2. & $\begin{array}{l}\text { Brain } \\
\text { Natriuretic } \\
\text { Peptide (BNP) }\end{array}$ & M25297 & $\begin{array}{l}\text { Cardiomyocyte-specific peptide hormones which is } \\
\text { constitutively expressed in the adult heart. }\end{array}$ & hsa-Mir-3934 & $\begin{array}{l}\text { He Q et al, 2002, } \\
\text { [PMID: } \\
\text { 12067842]. }\end{array}$ \\
\hline 3. & $\begin{array}{l}\text { Cardiac } \\
\text { Troponin } \mathrm{T} \\
\text { (TNNT2) }\end{array}$ & EU295527 & $\begin{array}{l}\text { A conspicuous substrate through which protein } \\
\text { kinase } C(P K C) \text { exerts its effect on cardiomyocyte } \\
\text { function. }\end{array}$ & $\begin{array}{l}\text { hsa-Mir-665 } \\
\text { hsa-Mir- } \\
4695-5 p\end{array}$ & $\begin{array}{l}\text { Sumandea MP et } \\
\text { al, 2003, [PMID: } \\
\text { 12832403]. }\end{array}$ \\
\hline 4. & $\begin{array}{l}\text { Cardiac } \\
\text { Troponin C } \\
\text { (TNNI3) }\end{array}$ & NM_017144 & $\begin{array}{l}\text { A highly specific regulatory protein in cardiac muscle } \\
\text { contraction and relaxation and specific means to } \\
\text { damage the myocardial damage in mammalian } \\
\text { species. }\end{array}$ & $\begin{array}{l}\text { hsa-Mir- } 4476 \\
\text { hsa-Mir- } \\
\text { 4763-3p }\end{array}$ & $\begin{array}{l}\text { Layland J et } \\
\text { al, 2005, [PMID: } \\
\text { 15769444]. }\end{array}$ \\
\hline 5. & $\begin{array}{l}\text { a-Actinin } \\
\text { (ACTC1) }\end{array}$ & NM_019183 & $\begin{array}{l}\text { A prominent marker gene involved in various types } \\
\text { of cell motility and is ubiquitously expressed in all } \\
\text { eukaryotic cells and defects in this gene shows dilated } \\
\text { and familial cardiomyopathy. }\end{array}$ & hsa-Mir-30d & $\begin{array}{l}\text { Hong-Kun Jiang } \\
\text { et al, 2010, } \\
\text { [PMID: } \\
\text { 20962418]. }\end{array}$ \\
\hline 6. & $\begin{array}{l}\beta-\mathrm{MHC} \\
(\mathrm{MyH})\end{array}$ & NM_017240 & $\begin{array}{l}\text { Expressed in the atria of failing adult hearts which } \\
\text { regulates cardiac contractility. }\end{array}$ & $\begin{array}{l}\text { hsa-Mir-4489 } \\
\text { hsa-Mir- } \\
\text { 4638-3p } \\
\text { hsa-Mir-4656 }\end{array}$ & $\begin{array}{l}\text { Nishi H et al, } \\
\text { 2011, [PMID: } \\
\text { 21149577]. }\end{array}$ \\
\hline
\end{tabular}

